\title{
ARTIGO
}

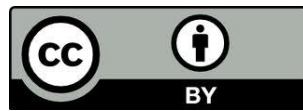

\section{O DEVER DE IMPARCIALIDADE DO ESTADO E O REGISTRO DAS ENTIDADES RELIGIOSAS NA JURISPRUDÊNCIA DO TRIBUNAL EUROPEU DE DIREITOS HUMANOS ANÁLISE DO CASO IGREJA METROPOLITANA DE BESSARÁBIA E OUTROS C. MOLDÁVIA}

\author{
The State's duty of impartiality and the registration of religious entities in the \\ Jurisprudence of the European Court of Human Rights \\ Analysis of the case Metropolitan Church of Bessarabia and others v. Moldova
}

\author{
André Fagundes \\ Universidade de Coimbra \\ Mestre em Ciências Jurídico-Políticas - Menção em Direito Constitucional \\ andrecep@gmail.com
}

\begin{abstract}
RESUMO: O presente artigo busca examinar alguns elementos do direito à liberdade religiosa, nomeadamente o dever de imparcialidade do Estado e o direito ao registro das entidades religiosas. A este propósito, analisou-se o acórdão proferido no processo n. 45.701/99 pela $1^{\text {a }}$ Seção do Tribunal Europeu de Direitos Humanos em 14/12/2001, cotejando-o com outros julgados do referido Tribunal e abordando diversas declarações e tratados internacionais que tratam da matéria. Verificou-se que o Estado, ao realizar um juízo de valor sobre a crença religiosa e suas formas de manifestação, viola o seu dever de imparcialidade, nos termos do artigo $9^{\circ}$ da Convenção Europeia de Direitos Humanos.
\end{abstract}

Palavras-chave: Liberdade Religiosa; Dever de imparcialidade; Reconhecimento oficial; Sociedade democrática

ABSTRACT: This article aims to examine some elements of the right to religious freedom, namely the State's duty of impartiality and the right to registration of religious entities. For this purpose, it analysed the judgment passed in case n. 45.701/99, by the 1st Section of the European Court of Human Rights on $14 / 12 / 2001$, comparing it with other judges of the aforementioned Court and speaking of several declarations and international treaties about the matter. It was verified that the State, when accomplishing a judgment of value on the religious faith and their manifestation forms, violates its impartiality duty, according to Article 9 of the European Convention on Human Rights.

Keywords: Religious Freedom; Duty of impartiality; Official recognition; Democratic society. 


\section{Introdução}

Em virtude das atrocidades cometidas na Segunda Guerra Mundial, o Congresso da Europa reuniu-se para tomar medidas que pudessem efetivar alguns dos direitos previstos na Declaração Universal de Direitos Humanos. Para tanto, criou-se o Conselho da Europa, que elaborou, em 1950, a Convenção para a Proteção de Direitos Humanos e das Liberdades Fundamentais, também conhecida como Convenção Europeia de Direitos Humanos «doravante "CEDH”», com a previsão de uma série de direitos e liberdades civis e políticas, bem como a criação do Tribunal Europeu de Direitos Humanos «doravante "TEDH"», para garantir o respeito dos compromissos assumidos pelos Estados signatários.

Dentre os direitos tutelados pela CEDH está o direito à liberdade religiosa, previsto no artigo $9^{\circ}$, juntamente com a liberdade de pensamento e de consciência. Para sua proteção, o interessado deve apresentar uma queixa perante o TEDH, que analisará se determinada conduta (omissiva ou comissiva) do Estado interfere no exercício do referido direito. Em caso positivo, o TEDH verifica se essa ingerência, se concretizada, seria lícita e necessária numa sociedade democrática para a realização de um ou mais objetivos legítimos previstos no n. 2 do art. $9^{\circ}$. Isto é, realiza o controle através da metódica da proporcionalidade.

Cumpre assinalar, ainda, que os acórdãos proferidos pelo TEDH, por força do disposto no n. ${ }^{\circ} 1$ do artigo $46^{\circ}$ da $\mathrm{CEDH}$, são vinculantes aos 47 Estados membros do Conselho da Europa.

O presente trabalho, através do exame analítico dos fundamentos adotados pelo TEDH e dos diplomas internacionais pertinentes, abordará a interessante problemática envolvendo o direito ao registro das entidades religiosas e o dever de imparcialidade do Estado.

\section{Breve síntese do caso}

A Igreja Metropolitana de Bessarábia é uma igreja ortodoxa autônoma que funciona sob a autoridade do Patriarcado de Bucareste (a Igreja Ortodoxa Romena). Visando obter o seu reconhecimento oficial na Moldávia, pleiteou, em outubro de 1992, o seu registro, em atendimento à legislação local (Religious Denominations Act - Lei n. 979-XII, de 24/03/1992), que exige que as entidades religiosas ativas no país sejam reconhecidas por decisão do governo. No entanto, não obteve resposta do pedido. 
No ano de 1995, após diversas reiterações do pedido, o Departamento de Assuntos Religiosos negou o registro. Diante disso, a Igreja Metropolitana da Bessarábia ingressou com uma ação judicial buscando a anulação da decisão administrativa. $\mathrm{O}$ Tribunal local julgou procedente $\mathrm{o}$ pedido, ordenando $\mathrm{o}$ reconhecimento da mencionada Igreja.

O Ministério Público recorreu ao Supremo Tribunal de Justiça, o qual anulou a decisão de primeira instância, sob o fundamento de que os tribunais não têm competência para apreciar o pedido de reconhecimento da Igreja requerente.

Posteriormente a Igreja Metropolitana de Bessarábia formulou novos pedidos administrativos de registro, os quais foram rejeitados e novamente levados à discussão judicial. No Tribunal de Recurso o governo alegou que o caso dizia respeito a um conflito eclesiástico dentro da Igreja Ortodoxa na Moldávia (a Igreja Metropolitana da Moldávia), que só poderia ser resolvido pelas Igrejas Ortodoxa da Romênia e da Rússia, e que qualquer reconhecimento da Igreja Metropolitana de Bessarábia provocaria conflitos na comunidade ortodoxa.

Todavia, o Tribunal de Recursos afastou tais alegações e deu provimento ao recurso da Igreja, sob o fundamento de que os parágrafos $1 .^{\circ}$ e $2 .^{\circ}$ do artigo $31^{\circ}$ da Constituição da Moldávia garantem a liberdade de consciência e que essa liberdade deve ser exercida com espírito de tolerância e respeito com as entidades. Além do que, as diferentes religiões são livres para organizar-se de acordo com os seus estatutos, desde que não contrariem as leis do país.

O governo então recorreu ao Supremo Tribunal de Justiça, que decidiu por anular o acórdão do juízo a quo, eis que o recurso interposto pela Igreja tinha sido intempestivo. A Corte consignou que, de todo modo, a recusa do pedido da Igreja não violava a sua liberdade religiosa, eis que os fiéis poderiam manifestar livremente as suas crenças, ter acesso às igrejas e que não provaram qualquer obstáculo à prática da sua religião.

O Supremo Tribunal de Justiça considerou, por fim, que o caso era simplesmente uma disputa administrativa dentro de uma única Igreja, que só poderia ser resolvida pela Igreja Metropolitana da Moldávia, uma vez que qualquer intromissão do Estado no assunto poderia agravar a situação. Sustentou, por fim, que a recusa do Estado em intervir neste conflito era compatível com o n. 2 do artigo $9^{\circ}$ da CEDH. 
Em março de 1999, a Igreja Metropolitana da Bessarábia pleiteou novamente ao governo o seu reconhecimento. O Primeiro-Ministro negou o pedido com o fundamento de que a Igreja requerente não era uma denominação religiosa no sentido jurídico, mas sim um grupo cismático dentro da Igreja Metropolitana da Moldávia, de modo que o reconhecimento da Igreja requerente representaria uma ingerência do Estado nos assuntos da Igreja Metropolitana da Moldávia e que isso agravaria a situação delicada em que se encontrava a Igreja.

Inconformados com o impedimento de obterem o reconhecimento oficial por meio do registro e com a ocorrência de diversos incidentes pelo país contrários à livre manifestação de suas crenças, inclusive com a prisão de alguns membros e a destruição de seus bens, a Igreja Metropolitana de Bessarábia e mais doze fiéis moldavos recorreram ao TEDH, alegando que a recusa das autoridades moldavas em reconhecer a Igreja Metropolitana da Bessarábia violava a sua liberdade religiosa e de associação, uma vez que só as religiões reconhecidas pelo governo poderiam ser praticadas na Moldávia.

Afirmaram, outrossim, que a liberdade de manifestar a sua religião coletivamente foi frustrada pelo fato de terem sido proibidos de se reunirem para fins religiosos, além da ausência total de proteção judicial de seus bens.

Em sua defesa, o governo moldavo argumentou que a Igreja requerente, como Igreja Cristã Ortodoxa, não era uma nova denominação, uma vez que o cristianismo ortodoxo tinha sido reconhecido na Moldávia em fevereiro de 1993, ao mesmo tempo que a Igreja Metropolitana da Moldávia. Não havia absolutamente nenhuma diferença, do ponto de vista religioso, entre a Igreja requerente e a Igreja Metropolitana da Moldávia.

Aduziu, ainda, que a criação da Igreja requerente tinha sido, na realidade, uma tentativa de criar um novo órgão administrativo dentro da Igreja Metropolitana da Moldávia, de modo que o Estado não poderia intrometer-se num conflito interno da Igreja sem violar seu dever de imparcialidade em matéria religiosa.

Por fim, o governo afirmou que este conflito, aparentemente administrativo, dissimulava um conflito político entre a Romênia e a Rússia. Intervir e reconhecer a Igreja recorrente - que considerava ser um grupo cismático - traria consequências prejudiciais à independência e à integridade territorial da jovem República da 


\section{Moldávia. ${ }^{1}$}

$\mathrm{Na}$ apreciação do caso, o TEDH concluiu, por unanimidade de votos, que houve violação ao artigo $9^{\circ}$ da CEDU, tendo em vista que, embora a ingerência estatal estivesse prevista em lei na persecução de um objetivo legítimo - qual seja, a proteção da ordem e da segurança pública -, tal interferência não foi necessária numa sociedade democrática.

O TEDH observou, ainda, que é incompatível com o dever de imparcialidade do Estado avaliar a legitimidade das crenças religiosas. Caberia ao Estado, nesses casos, assegurar que grupos conflitantes se tolerassem mutuamente, ainda que originários de uma mesma organização.

\section{Do dever de imparcialidade do Estado}

O TEDH, nos parece, andou bem ao decidir a questão, pois o governo moldavo, ao negar o registro da Igreja requerente, sob o fundamento de que se tratava apenas de um grupo cismático dentro da Igreja Ortodoxa, falhou em seu dever de imparcialidade.

Num Estado laico, como o ora analisado, a recusa do reconhecimento de determinada confissão religiosa - com o propósito de forçá-la a se reunir sob uma liderança unificada, contra as suas aspirações - constitui nítida interferência arbitrária na liberdade religiosa dos cidadãos.

Conquanto o governo detenha o poder de regulamentar as diversas religiões existentes em seu território, podendo, inclusive, impor determinadas restrições ao exercício da liberdade religiosa, como veremos adiante, deve permanecer neutro em relação ao mérito das crenças religiosas.

Vale dizer, o direito à liberdade de religião, tal como assegurado pela CEDU, exclui qualquer poder discricionário por parte do Estado para determinar a legitimidade das crenças religiosas e suas formas de manifestação. Do contrário, estaríamos diante de um árbitro de dogmas religiosos.

No caso em tela, quando da recusa do registro, as autoridades locais fizeram um juízo de valor sobre a doutrina religiosa em si, isto é, sobre o seu mérito, quando em verdade deveriam ater-se tão-somente à análise do preenchimento dos requisitos legais.

Em julgado semelhante (Hasan e Chaush c. Bulgária, n. 30.985/96) - em que se

\footnotetext{
${ }^{1}$ Visando melhor esclarecimento da questão, vale destacar que no ano de 1991 a então República Socialista Soviética da Moldávia declarou sua independência da União Soviética, durante o processo de dissolução da URSS.
} 
discutiu o dever de imparcialidade estatal em matéria de registro administrativo das comunidades religiosas -, o TEDH consignou que em sociedades democráticas o Estado não deve impor que entidades religiosas divididas sejam submetidas a uma única direção.

Por conseguinte, o papel das autoridades, nestas circunstâncias, não é eliminar a causa de tensão com a supressão do pluralismo religioso. Absolutamente. O Estado deve, em todas as suas esferas, tomar medidas que promovam a tolerância, a convivência pacífica e o efetivo respeito entre as diversas organizações religiosas.

Nesse sentido, a Declaração de Princípios sobre a Tolerância ${ }^{2}$ estabelece que no "âmbito do Estado, a tolerância exige justiça e imparcialidade na legislação, na aplicação da lei e no exercício dos poderes judiciário e administrativo ” (artigo 2.1).

No caso em exame, nota-se claramente que tanto o poder executivo quanto o poder judiciário moldavo falharam em seu mister de respeito às diversidades religiosas ao negar o registro da Igreja Metropolitana da Bessarábia. ${ }^{3}$

A aceitação das diferentes crenças religiosas não se trata apenas de um princípio relevante ou de um dever de ordem ética, mas uma necessidade política e jurídica, indispensável para a consolidação da paz e para o progresso econômico e social dos povos. $^{4}$ De fato, a interação harmoniosa entre pessoas e grupos com identidades variadas é essencial para a realização da coesão social. ${ }^{5}$

Um dos fundamentos da liberdade religiosa é a garantia de que as pessoas podem seguir sua religião, ainda que seja diferente da maioria. É justamente a acomodação das crenças minoritárias que distingue a democracia de um estado totalitário (TRIGG, 2012, p. 146).

Para o efetivo cumprimento do respeito à pluriconfessionalidade, o Estado não deve determinar o que constitua ou não uma religião ou crença, como bem observou o TEDH em outro importantíssimo julgado sobre o tema (Seção de Moscou do Exército de Salvação c. Rússia, n. 72.881/01, §§ 57-58).

Vale destacar, por oportuno, que para determinada convicção pessoal ou coletiva se valer do direito à "liberdade de pensamento, de consciência e de religião" assegurado pelo artigo $9^{\circ}$ da CEDU, abaixo transcrito -, deve atingir um certo nível de

\footnotetext{
${ }^{2}$ Aprovada pela Conferência Geral da UNESCO em sua 28ª reunião, em 16 de novembro de 1995.

${ }^{3}$ Tal dever decorre também do disposto no art. $22^{\circ}$ da Carta dos Direitos Fundamentais da União Europeia (CDFUE).

${ }^{4}$ Consoante o disposto no preâmbulo e no n. 1 do artigo $1^{\circ}$ da Declaração de Princípios sobre a Tolerância.

${ }^{5}$ Cf. Seção de Moscou do Exército de Salvação c. Rússia, já referido, § 61.
} 
coerência, seriedade e importância. ${ }^{6}$ Desde que essas condições estejam satisfeitas, o dever de imparcialidade do Estado é incompatível com a avaliação sobre a legitimidade das crenças religiosas e a forma como essas crenças são expressas. ${ }^{7}$

\begin{abstract}
ARTIGO $9^{\circ}$
Liberdade de pensamento, de consciência e de religião

1. Qualquer pessoa tem direito à liberdade de pensamento, de consciência e de religião; este direito implica a liberdade de mudar de religião ou de crença, assim como a liberdade de manifestar a sua religião ou a sua crença, individual ou coletivamente, em público e em privado, por meio do culto, do ensino, de práticas e da celebração de ritos.

2. A liberdade de manifestar a sua religião ou convicções, individual ou coletivamente, não pode ser objeto de outras restrições senão as que, previstas na lei, constituírem disposições necessárias, numa sociedade democrática, à segurança pública, à proteção da ordem, da saúde e moral públicas, ou à proteção dos direitos e liberdades de outrem.
\end{abstract}

Do mesmo modo, decorre da proteção do mencionado artigo, ${ }^{8}$ a vedação ao Estado em interferir sobre a doutrina professada pelas religiões. ${ }^{9}$ Como não poderia deixar de ser, a religião e as convicções são, essencialmente, pessoais e subjetivas, de modo que não compete ao Estado - sob pena de violação ao dever de imparcialidade impor, de maneira direta ou indireta, uma linha interpretativa a respeito dos preceitos professados, ainda que contrários a um entendimento dominante como, por exemplo, na crença de determinadas seitas ${ }^{10}$ sobre a existência da reencarnação e sua conformidade com os ensinos da fé cristã. ${ }^{11}$

Com efeito, a definição e a interpretação dos princípios doutrinários integra, indubitavelmente, a esfera da fé religiosa; é elemento fundamental, que está no núcleo da convicção religiosa; constitui verdadeira reserva absoluta da confissão religiosa,

\footnotetext{
${ }^{6}$ A esse respeito, vale mencionar que em 2005 foi oficialmente reconhecida pelos Estados Unidos a "Igreja do Monstro do Espaguete Voador (Monsevol)". Tal decisão, entretanto, não nos parece ter sido acertada, haja vista a nítida origem satírica da entidade, com declarada intenção de protesto contra o conselho educacional de uma escola de Dover, na Pensilvânia. Sobre a necessidade de a crença ser sincera, ver acórdão Syndicat Northcrest v. Amselem, 2004 SCC 47, [2004] 2 S.C.R. 551, da Suprema Corte do Canadá.

${ }^{7}$ Cf. Eweida e outros c. Reino Unido, n. 48.420/10, 59.842/10, 51.671/10 e 36.516/10, § 81.

${ }^{8} \mathrm{O}$ direito previsto no artigo $9^{\circ}$ da CEDH corresponde ao artigo $10^{\circ}$ da CDFUE, inclusive o seu âmbito e sentido, conforme expressamente dispõe o artigo $52^{\circ}, 3$, da referida Carta.

${ }^{9}$ Evidentemente não estão incluídas aqui as manifestações que resultem em propaganda a favor da guerra ou em apologia ao ódio nacional, racial ou religioso, que constitua uma incitação à discriminação, à hostilidade ou à violência, conforme preceitua o artigo 20 do Pacto Internacional sobre os Direitos Civis e Políticos.

${ }^{10}$ Vale ressaltar que o Pacto Internacional sobre os Direitos Civis e Políticos prevê uma garantia especial às minorias religiosas contra as ingerências do Estado: “Artigo 27. Nos Estados em que existam minorias étnicas, religiosas ou linguísticas, as pessoas pertencentes a essas minorias não devem ser privadas do direito de ter, em comum com os outros membros do seu grupo, a sua própria vida cultural, de professar e de praticar a sua própria religião ou de empregar a sua própria língua." (grifo nosso).

${ }^{11}$ A respeito do tema, merece destaque o brilhante posicionamento adotado pelo Tribunal Constitucional Português, ao assinalar que "qualquer forma de dirigismo cultural fere o bem comum e mina os alicerces do Estado de direito. O Estado não pode, pois, impor aos cidadãos quaisquer formas de concepção do homem, do mundo e da vida." (Tribunal Constitucional. Relator: Alves Correia, Proc. n. 88-0322, j. 17/02/1993).
} 
funcionando como norma definidora de competências negativas do Estado (MACHADO, 1996, p. 247).

Considerando que o Estado não está, e nem deveria estar, na posição de árbitro dos dogmas religiosos, ${ }^{12}$ ao arbitrar um entendimento como sendo o correto, nitidamente infringe o seu dever de imparcialidade imposto pelo princípio da separação, e consequentemente viola o direito à liberdade de religião, tal como ocorre quando há imisção estatal sobre os rituais pelos quais a crença se manifesta. ${ }^{13}$

\section{Das restrições necessárias numa sociedade democrática}

$\mathrm{Na}$ fundamentação do acórdão, o TEDH reforçou o seu entendimento de que a liberdade de pensamento, de consciência e de religião, é um dos fundamentos de uma sociedade democrática. Trata-se de um dos elementos mais importantes que compõem, não só a identidade dos crentes e suas concepções de vida, mas também dos ateus, agnósticos, céticos e indiferentes. Destarte, o pluralismo - que tem sido conquistado ao longo dos séculos - é indissociável de uma sociedade democrática. ${ }^{14}$

Da análise do artigo $9^{\circ}$ da $\mathrm{CEDH}$, tem-se que a restrição à liberdade religiosa só está autorizada quando, prevista em lei, constitua disposição necessária à preservação do Estado democrático, à segurança pública, à proteção da ordem, da saúde e moral públicas, ou à proteção dos direitos e liberdades de terceiros. ${ }^{15}$

Cumpre assinalar que o Estado tem poderes para verificar se uma entidade esteja exercendo, sob aparente finalidades religiosas, atividades que sejam prejudiciais à população ou que possam pôr em perigo a segurança pública. Realmente, não se pode descartar que o programa de uma organização possa esconder objetivos e intenções distintos dos quais proclama. ${ }^{16}$

\footnotetext{
${ }^{12}$ Cf. Syndicat Northcrest v. Amselem, já referido.

13 Como bem advertem J. J. Gomes CANOTILHO e Vital MOREIRA (2007, p. 201), é elemento implícito da afirmação do princípio republicano o "estabelecimento da separação entre o Estado e as igrejas, com a consagração de um Estado não confessional e de um regime de liberdade religiosa".

${ }^{14}$ A esse respeito, Robert AUDI (2012, p. 66) destaca que onde há liberdade, deve haver espaço para o pluralismo. Nas sociedades em que a vida sociocultural é complexa, a liberdade praticamente salvaguarda o pluralismo.

${ }^{15} \mathrm{O}$ Pacto Internacional sobre os Direitos Civis e Políticos prevê, em seu art. $18^{\circ}$, n. ${ }^{\circ}$ 3, semelhante disposição. Com vistas à melhor esclarecer o alcance da referida norma, foi elaborado o Comentário Geral n. ${ }^{\circ} 22$, o qual, em razão de sua significativa importância, passamos a transcrever: "O artigo $18 .^{\circ}$ não está limitado na sua aplicação a religiões tradicionais ou a religiões e convicções com características institucionais ou práticas análogas às das religiões tradicionais. Assim, o Comitê vê com preocupação qualquer tendência a discriminar contra qualquer religião ou convicção, em particular as mais recentemente estabelecidas ou as que representam as minorias religiosas que possam ser objeto de hostilidade por parte de uma comunidade religiosa predominante." (grifo nosso). ${ }^{16}$ Cf. Manoussakis e outros c. Grécia, já referido, § 40; Stankov e a Organização Macedônia-Unida Ilinden v. Bulgária, n. 29.221/95 e 29.225/95, § 84; e Sidiropoulos e outros c. Grécia, n. 26.695/95, § 46.
} 
O TEDH considera, por exemplo, que o fato de uma entidade religiosa não apresentar às autoridades a descrição de seus preceitos fundamentais pode ser motivo suficiente para a recusa de sua inscrição, na medida em que pode representar um risco à sociedade democrática e os interesses fundamentais assegurados pelo $\mathrm{n}^{\circ} 2$ do artigo $9^{\circ}$ da $\mathrm{CEDH} .{ }^{17}$

A Corte pontuou também que, numa sociedade democrática, em que diferentes religiões coexistem dentro de uma mesma população, pode ser necessário o estabelecimento de restrições a essa liberdade para o fim de conciliar os interesses dos diversos grupos e garantir que todas as crenças sejam respeitadas.

No entanto, a fiscalização das atividades desenvolvidas, bem como a fixação das restrições à liberdade religiosa devem ser utilizadas com moderação e de forma compatível com as obrigações impostas por força da CEDH. ${ }^{18}$

De fato, considerando tratar-se de exceções à regra, o poder estatal deve ser interpretado de forma restrita, de modo que apenas razões convincentes e persuasivas podem ser capazes de justificar limitações à liberdade de religião e de associação. Qualquer intervenção deve corresponder a uma "necessidade social premente" e ser "proporcional ao objetivo legítimo perseguido". Por conseguinte, a caracterização do “necessário" não alberga noções vagas e flexíveis como "útil” ou “desejável”. ${ }^{19}$

Assim, além de estar em consonância com a lei e atender a um objetivo legítimo, a interferência do Estado deve satisfazer a exigência da proporcionalidade. Em situações como a ora analisada, a proporcionalidade está estreitamente ligada com a necessidade de manter o verdadeiro pluralismo religioso, inerente ao conceito de sociedade democrática. Considerando que "nenhuma medida restritiva de um direito deve ser admitida se com ela não se visar a promoção de um outro direito ou interesse geral" (SILVA, 2014, p. 53), tem-se que a decisão do governo moldavo não foi adequada.

Tentar resolver os conflitos existentes entre organizações religiosas através do impedimento do registro de uma delas é atuação absolutamente desproporcional, contrária à ideia de sociedade democrática, em que há pluralismo de ideias e de crenças.

Outro aspecto que merece atenção é o argumento do governo de que o pedido da

\footnotetext{
17 Cf. Cârmuirea Spirituală a Musulmanilor da República da Moldávia c. Moldávia, n. 12.282/02; Igreja da Cientologia de Moscou c. Rússia, § 93, n. 18.147/02; e Lajda e outros c. República Checa, n. 20.984/05.

${ }^{18}$ Cf. Testemunhas de Jeová de Moscou e outros c. Rússia, § 100, n. ${ }^{\circ} 302 / 02$.

${ }^{19}$ Cf. Seção de Moscou do Exército de Salvação c. Rússia, já referido, § 62; e Gorzelik e outros c. Polônia, n. ${ }^{\circ}$ $44.158 / 98, \S 92$.
} 
Igreja requerente estava pondo em causa a integridade territorial e a estabilidade social do país. Conquanto seja legítimo o Estado atuar na defesa da ordem e da segurança nacional, como mencionado, no caso em tela tal acusação revelou-se manifestamente infundada, visto que não havia qualquer elemento no processo que demonstrasse que a Igreja requerente exercia outras atividades para além das previstas em seus estatutos, nem mesmo que exercia qualquer atividade ilegal ou contrária à ordem pública.

Ao contrário do alegado pelo governo, a Declaração sobre os Direitos das Pessoas Pertencentes a Minorias Nacionais ou Étnicas, Religiosas e Linguísticas ${ }^{20}$ esclarece justamente que "a promoção e proteção dos direitos das pessoas pertencentes a minorias nacionais ou étnicas, religiosas e linguísticas contribuem para a estabilidade política e social dos Estados onde vivem essas pessoas" (grifo nosso). ${ }^{21}$

Efetivamente, a existência de uma sociedade pacífica e democrática só é possível com respeito à pluriconfessionalidade. ${ }^{22}$ À vista disso, o direito dos crentes à liberdade de religião assegurado pela CEDH abrange também a expectativa de que a comunidade terá permissão para funcionar pacificamente, podendo professar sua convicção sem qualquer intervenção injustificada do Estado (aqui incluído o Departamento de Assuntos Religiosos e o Poder Judiciário). ${ }^{23}$

\section{Do direito ao registro}

Conquanto o TEDH tenha declarado ser desnecessário determinar se no caso em análise houve violação ao artigo $11^{\circ}$ da Convenção ${ }^{24}$ - que garante a liberdade de reunião e associação -, o acórdão traz importantes considerações a respeito do direito ao registro de uma entidade religiosa, senão vejamos.

\footnotetext{
${ }^{20}$ Adotada pela Assembleia Geral das Nações Unidas na sua Resolução 47/135, de 18 de dezembro de 1992.

${ }^{21}$ Nos termos do preâmbulo da referida Declaração.

${ }^{22}$ Como bem pontua Roger TRIGG (2012, p. 08), Diretor Acadêmico do Centro de Estudos de Religião na Vida Pública de Kellogg College, da Universidade de Oxford, a questão da liberdade de consciência e da liberdade de religião surge na sua forma mais intensa quando posições minoritárias impopulares ou antiquadas estão em questão. A liberdade é salvaguardada apenas quando a maioria permite que as crenças que elas desaprovam sejam manifestadas.

${ }^{23}$ Ver Seção de Moscou do Exército de Salvação c. Rússia, já referido, § 71; e Hasan e Chaush c. Bulgária, já referido, $\S 62$.

${ }^{24}$ Artigo $11^{\circ}$. Liberdade de reunião e de associação:

1. Qualquer pessoa tem direito à liberdade de reunião pacífica e à liberdade de associação, incluindo o direito de, com outrem, fundar e filiar-se em sindicatos para a defesa dos seus interesses.

2. O exercício deste direito só pode ser objeto de restrições que, sendo previstas na lei, constituírem disposições necessárias, numa sociedade democrática, para a segurança nacional, a segurança pública, a defesa da ordem e a prevenção do crime, a proteção da saúde ou da moral, ou a proteção dos direitos e das liberdades de terceiros. O presente artigo não proíbe que sejam impostas restrições legítimas ao exercício destes direitos aos membros das forças armadas, da polícia ou da administração do Estado.
} 
O governo alegou em sua defesa que a recusa do registro não violou o direito à liberdade religiosa dos requerentes, haja vista que, por serem cristãos ortodoxos, poderiam manifestar suas crenças dentro de outra Igreja Cristã Ortodoxa já reconhecida pelo Estado, a saber, a Igreja Metropolitana da Moldávia.

No entanto, como bem observado pelo TEDH, além do Estado não poder avaliar a legitimidade dessa organização religiosa, a legislação local somente permitia que as religiões reconhecidas por decisão do governo fossem praticadas na Moldávia, de modo que a recusa em registrar a Igreja requerente equivalia na sua proibição de operar, quer como corpo litúrgico, quer como associação.

Vale dizer, sem o reconhecimento legal, o exercício das atividades da Igreja requerente ficavam impraticáveis, eis que seus sacerdotes não podiam celebrar o culto, seus membros ficavam impedidos de reunir-se para manifestar sua religião e ainda, não tendo personalidade jurídica, a entidade não tinha direito à proteção judicial dos seus bens, bem como autorização para defender-se contra atos de intimidação.

Cumpre enfatizar que, não obstante a crença seja essencialmente pessoal e subjetiva, sua manifestação é tradicionalmente realizada em conjunto, através de estruturas organizadas. Não é por outro motivo que o n. $^{\circ} 1$ do $\operatorname{artigo} 9^{\circ}$ da CEDH garante o direito de manifestar a religião de forma coletiva, no seio de comunidades religiosas.

Nessa linha, a jurisprudência do TEDH firmou o entendimento de que a recusa da concessão do status de entidade jurídica à determinada organização religiosa configura severa restrição à sua capacidade de praticar a religião, mesmo nos casos em que a ausência de personalidade jurídica possa ser compensada, em parte, pela criação de associações auxiliares (auxiliary associations). Assim, ainda que não haja demonstração de prejuízo ou dano à comunidade religiosa - questão que só é relevante no contexto do artigo $41^{\circ}$ da $\mathrm{CEDH}$-, o impedimento de seu registro constitui injustificada discriminação. ${ }^{25}$

Com efeito, o direito ao reconhecimento oficial de uma igreja é corolário lógico do respeito à liberdade religiosa. Trata-se de um natural desdobramento, uma faceta do direito à liberdade de religião. Como observado, a não efetivação do registro acaba por,

${ }^{25}$ Cf. Comunidade Religiosa das Testemunhas de Jeová e outros c. Áustria, n. 40.825/98, § 67. 
na prática, esvaziar - significativa ou mesmo integralmente - o conteúdo do direito em análise.

A respeito do tema, vale mencionar que o Comentário Geral $n^{\circ}{ }^{\circ} 18$ (Não Discriminação) sobre o Pacto Internacional sobre os Direitos Civis e Políticos, bem como a Declaração sobre a Eliminação de Todas as Formas de Intolerância e Discriminação Baseadas na Religião ou Convicção (n. 2 do artigo $2^{\circ}$ ), esclarecem que configura intolerância e discriminação baseadas na religião, inter alia, quaisquer restrições que tenham por objetivo ou mesmo como consequência a supressão ou limitação do reconhecimento, ou do exercício de todos os direitos e liberdades em condições de igualdade.

Além do mais, o artigo $11^{\circ}$ da $\mathrm{CEDH}$ assegura que os cidadãos devem ser capazes de formar uma pessoa jurídica, ${ }^{26}$ a fim de que possam agir coletivamente em um campo de interesse mútuo - incluindo, obviamente, os propósitos religiosos -, sem interferências arbitrárias do Estado. Caso contrário, tal direito seria destituído de qualquer significado. ${ }^{27}$

Convém destacar, last but not least, que muito embora a Igreja requerente tenha tido acesso aos Tribunais nacionais, os recursos não foram efetivos, na medida em que a decisão final do Supremo Tribunal de Justiça da Moldávia deixou de responder às suas principais reivindicações, nomeadamente o desejo de praticar sua religião em organização própria, bem como a busca pela tutela jurisdicional de seus bens. Além disso, a legislação local não previa nenhuma disposição específica para dirimir os casos em que há litígio no procedimento de registro, motivo pelo qual o TEDH considerou que houve violação do art. $13^{\circ}$ da $\mathrm{CEDH} .{ }^{28}$

A partir da presente análise, temos que houve grande acerto do TEDH ao enfrentar a questão, pois a recusa do registro da Igreja Metropolitana da Bessarábia por estar baseada em meras suposições de perigo à ordem pública e a segurança

\footnotetext{
${ }^{26}$ Tal garantia está igualmente prevista no artigo $20^{\circ}$, n. 1, da Declaração Universal de Direitos do Homem; no artigo 22, $\S 1^{\circ}$ do Pacto Internacional sobre os Direitos Civis e Políticos; no artigo $2^{\circ}$, n. $^{\circ} 4$, da Declaração sobre os Direitos das Pessoas Pertencentes a Minorias Nacionais ou Étnicas, Religiosas e Linguísticas; e no artigo $6^{\circ}$, alínea $b$ ), da Declaração sobre a Eliminação de Todas as Formas de Intolerância e Discriminação Baseadas na Religião ou Convicção;

${ }^{27}$ Cf. Seção de Moscou do Exército de Salvação c. Rússia, já referido, §§ 58-59.

${ }^{28}$ Artigo $13^{\circ}$. Direito a um recurso efetivo: Qualquer pessoa cujos direitos e liberdades reconhecidos na presente Convenção tiverem sido violados tem direito a recurso perante uma instância nacional, mesmo quando a violação tiver sido cometida por pessoas que atuem no exercício das suas funções oficiais.
} 
nacional - mostra-se injustificada e constitui, por conseguinte, violação ao direito à liberdade de religião assegurado no artigo $9^{\circ}$ da CEDH. 


\section{Referências}

AUDI, Robert. "Natural Reason, Religious Conviction". in Law, State and Religion in the New Europe. Debates and Dilemmas. Edited by ZUCCA, Lorenzo; UNGUREANU, Camil. Cambridge: Cambridge University Press.

CANOTILHO, José Joaquim Gomes; MOREIRA, Vital. Constituição da República Portuguesa Anotada. v. 1. 4. ed. Coimbra: Coimbra.

MACHADO, Jónatas Eduardo Mendes. Liberdade religiosa numa comunidade constitucional inclusiva: dos direitos da verdade aos direitos dos cidadãos. Coimbra: Coimbra.

SILVA, Suzana Tavares da. Direitos fundamentais na arena global. 2. ed. Coimbra: Impressa da Universidade de Coimbra.

TRIGG, Roger. Equality, Freedom, \& Religion. Oxford: Oxford University Press.

Recebido: 19/10/2017

Received: 10/19/2017

Aprovado: 23/11/2017

Approved: 11/23/2017 